\title{
Thymbra capitata (L.) Cav. and Rosmarinus officinalis (L.) Essential Oils: In Vitro Effects and Toxicity on Swine Spermatozoa
}

\author{
Alberto Elmi ${ }^{1}$ (D), Domenico Ventrella ${ }^{1, *}$ (D), Francesca Barone ${ }^{1}$, Gianfranco Filippini ${ }^{2}$, \\ Stefania Benvenuti ${ }^{3}$, Annamaria Pisi ${ }^{2}$, Maurizio Scozzoli ${ }^{4}$ and Maria L. Bacci ${ }^{1}$ \\ 1 Department of Veterinary Medical Sciences, University of Bologna, Via Tolara di Sopra 50, \\ 40064 Ozzano dell'Emilia, Italy; alberto.elmi2@unibo.it (A.E.); francesca.barone7@unibo.it (F.B.); \\ marialaura.bacci@unibo.it (M.L.B.) \\ 2 Department of Agricultural Sciences, University of Bologna, Via Fanin 44, 40127 Bologna, Italy; \\ gianfranco.filippini@unibo.it (G.F.); annamaria.pisi@unibo.it (A.P.) \\ 3 Department of Life Sciences, University of Modena and Reggio Emilia, Via Giuseppe Campi 103, \\ 41125 Modena, Italy; stefania.benvenuti@unimore.it \\ 4 APA-CT S.r.l., via Sacco Nicola 22, 47122 Forlì, Italy; maurizio@apabio.it \\ * Correspondence: domenico.ventrella2@unibo.it; Tel.: +39-051-2097923
}

Received: 16 November 2017; Accepted: 5 December 2017; Published: 6 December 2017

\begin{abstract}
Essential oils possess a variety of biological properties (i.e., antioxidant, antibacterial, and cytotoxic) that could possibly be applied in reproductive medicine, but their effects on spermatozoa are still partially unknown. The aim of the study was to describe the effects of Thymbra capitata (L.) Cav. and Rosmarinus officinalis (L.) essential oils on the main morpho-functional parameters of swine spermatozoa. Essential oils were preliminary characterized by gas chromatography and added with emulsifiers to facilitate diffusion. Experimental samples were prepared by suspending a fixed number of spermatozoa in $5 \mathrm{~mL}$ of medium with 10 different concentrations of essential oil $(0.2-2 \mathrm{mg} / \mathrm{mL}$, at intervals of 0.2$)$. After $3 \mathrm{~h}$ of incubation, samples were analyzed for $\mathrm{pH}$, viability, objective motility, and acrosome status. Results showed that the effects of the essential oils are concentration-dependent and that $R$. officinalis is well tolerated up to $0.6 \mathrm{mg} / \mathrm{mL}$. T. capitata impaired the spermatozoa starting from the lowest concentration, with complete spermicidal effect from $0.4 \mathrm{mg} / \mathrm{mL}$. The patterns of damage, confirmed by SEM, were different and quite distinct. As expected, spermatozoa proved to be sensitive to external stimuli and capable of showing different functional patterns, providing interesting insights to the action/toxicity mechanisms. The results of the present work represent the first step towards the systematic characterization of the effects of these compounds on spermatozoa. This kind of studies are necessary to strengthen the idea of future applications of essential oils in the reproductive field due to their antioxidant, antibacterial, or spermicidal properties.
\end{abstract}

Keywords: essential oils; Thymbra capitata; Rosmarinus officinalis; swine spermatozoa; in vitro cytotoxicity

\section{Introduction}

Looking back in history, it is safe to say that traditional medicine has used plants and their derivatives in order to cure and prevent diseases for centuries. During the last decades, the scientific community, in particular the medical one, has witnessed a considerably growing interest towards the application of essential oils (EOs) that are the products of the secondary metabolism of aromatic plants represented by complex mixtures of several compounds, including terpenoids and 
phenylpropanoids [1,2]. Essential oils and their constituents are indeed effective against a large variety of organisms, including bacteria [3,4], viruses [5,6], and fungi [7]. Moreover, some constitutive components of EOs have been proven to have important antioxidant effects [8]. Nonetheless, it has been acknowledged that those substances show strong toxic activities when applied to different cell populations, including fibroblasts and epithelial cells, monocytes, neutrophils, and also spermatozoa $[1,9,10]$, however without specific cellular targets $[8,11]$.

All the above-mentioned properties, both positive and negative, initiate an extremely interesting discussion related with their application in the reproductive field, both human and veterinary. The toxic effects are probably more investigated and exploited in the human reproductive area, where spermicidal medical devices are constantly being designed $[1,10,12]$. On the other hand, molecules with proven antibacterial and antioxidant properties are necessary in veterinary artificial insemination, where refrigeration of the inseminating doses represents a zootechnical routine, for example in swine. This fact stems from the necessity to find alternatives to the use of antibiotics that is increasingly being limited by the European Commission [13] and to find molecules capable of ensuring improved quality and high fertility of the male gametes.

Spermatic cells represent a good model for in vitro toxicological evaluation of several compounds that can affect the reproductive process such as smoke, nicotine [14,15], and other substances [16]. The use of spermatozoa collected from humans unfortunately has several ethical and legislative limitations, thus, animals' sperm is often used as a translational model. As opposed to macaques, which are probably considered as the overall "gold standard" animal models, porcine spermatozoa are collected using non-invasive techniques (e.g., hand-gloved technique) from trained animals that do not require any sedation and provide high-quality samples [17]. To date, only few EOs, including Trachyspermum ammi [10] and Thymus mumbianus [1], have been tested on human spermatozoa showing spermicidal capabilities. The mechanism of actions of these compounds are still partially unknown and potentially extremely variable, thus, specific studies for each EO on different cell models are necessary. Concerning animal spermatozoa, in particular porcine ones, only preliminary data regarding the effects of a combination of two EOs has been reported [18].

The aim of the present study was to assess and describe the effects of Thymbra capitata (L.) Cav. [=Coridothymus capitatus (L.) Rchb.f., Thymus capitatus Hoff et Link.] and Rosmarinus officinalis (L.) essential oils on the main morpho-functional parameters of swine spermatozoa. These plants, belonging to the Lamiaceae family, are endemic and extremely common to the Mediterranean Basin and are indeed proven to show a variety of biological activities $[19,20]$ with possible applications in zootechnical and reproductive medicine. Moreover, preliminary toxicological screening tests on spermatozoa may provide interesting information regarding the mechanisms of action of these compounds.

\section{Results}

\subsection{Chemical Composition of the EOs}

The chemical composition of T. capitata (Tc) and R. officinalis (Ro) EOs used in the present study are summarized in Tables 1 and 2, respectively. Carvacrol was the main component of Tc EO (65.2\%), followed by p-Cymene (12.28\%) and $\gamma$-terpinene (5.62\%). This particular composition resembles what already described in literature [21].

Table 1. Composition of the essential oil of Thymbra capitata (L.) Cav.

\begin{tabular}{ccc}
\hline Compounds & LRI $^{\mathbf{1}}$ & Area $\%$ \\
\hline$\alpha$-Thujene & 927 & 0.71 \\
$\alpha$-Pinene & 933 & 0.96 \\
Camphene & 948 & 0.15 \\
$\beta$-Pinene & 976 & 0.13 \\
\hline
\end{tabular}


Table 1. Cont.

\begin{tabular}{ccc}
\hline Compounds & LRI $\mathbf{1}^{\mathbf{1}}$ & Area $\%$ \\
\hline$\beta$-Myrcene & 993 & 1.37 \\
$\alpha$-Phellandrene & 1006 & 0.16 \\
$\alpha$-Terpinene & 1017 & 1.31 \\
p-Cymene & 1026 & 12.28 \\
Limonene & 1029 & 0.45 \\
$\gamma^{- \text {Terpinene }}$ & 1060 & 5.62 \\
trans-sabinene hydrate & 1067 & 0.09 \\
$\alpha$-Terpinolene & 1089 & 0.21 \\
Linalool & 1102 & 2.37 \\
Borneol & 1167 & 0.18 \\
Terpinen-4-ol & 1179 & 0.7 \\
Thymol & 1296 & 3.49 \\
Carvacrol & 1312 & 65.2 \\
$\beta$-Caryophyllene & 1426 & 1.92 \\
$\alpha$-Humulene & 1456 & 0.11 \\
Caryophyllene oxide & 1594 & 0.12 \\
\hline Total & & 97.54 \\
\hline
\end{tabular}

Table 2. Composition of the essential oil of Rosmarinus officinalis (L.).

\begin{tabular}{ccc}
\hline Compounds & LRI $^{\mathbf{1}}$ & Area $\%$ \\
\hline$\alpha$-Pinene & 936 & 23.55 \\
Camphene & 949 & 10.16 \\
$\beta$-Pinene & 977 & 5.39 \\
$\beta$-Myrcene & 993 & 1.88 \\
p-Cymene & 1026 & 2.8 \\
1,8-Cineole & 1034 & 21.36 \\
Linalool & 1103 & 0.96 \\
Camphor & 1145 & 22.03 \\
Borneol & 1168 & 2.84 \\
Terpinen-4-ol & 1180 & 0.05 \\
$\alpha$-Terpineol & 1193 & 2.45 \\
Bornyl acetate & 1290 & 1.38 \\
$\beta$-Caryophyllene & 1427 & 1.19 \\
Caryophyllene oxide & 1594 & 0.17 \\
\hline Total & & 96.22 \\
\hline
\end{tabular}

Regarding Ro EO, $\alpha$-pinene (23.55\%), camphor (22.03\%), and 1.8-cineole (21.36\%) were almost equally represented, followed by camphene $(10.16 \%)$ and $\beta$-pinene $(5.39 \%)$. When compared to the analyses of Ro EOs in the literature, the one used in this study seems to be similar with the exception of the relatively higher quantity of camphor [19].

\subsection{Semen Morpho-Functional Evaluations}

The descriptive statistics regarding the effects of the two tested essential oils on the main morpho-functional characteristics of semen are reported in Table S1 (Tc) and S2 (Ro).

The ANOVA outputs showed that the effects of both EOs were statistically significant with regard to sperm viability (V) (Tc $p<0.0001$; Ro $p<0.0001)$, total motility (TotM) (Tc $p<0.0001 ;$ Ro $p<0.0001$ ), progressive motility (ProgM) (Tc $p<0.0001$; Ro $p<0.0001$ ), and acrosome reaction (AR) (Tc $p<0.0001$; Ro $p=0.0036$ ). The analyses of variance for $\mathrm{pH}$, for both EOs, did not show any difference (Tc $p=0.9966$; Ro $p=0.9999)$. 
The effects on sperm viability of the different concentrations of EOs compared to the control samples are represented in Figure 1. Tc EO determined a significant reduction in V starting from the lowest tested concentration of $0.2 \mathrm{mg} / \mathrm{mL}(p=0.005)$, with stronger effects from $0.4 \mathrm{mg} / \mathrm{mL}$ up to $2 \mathrm{mg} / \mathrm{mL}(p<0.0001)$. No significant differences were detected for $\mathrm{V}$ of spermatozoa treated with Ro EO at concentrations ranging from $0.2 \mathrm{mg} / \mathrm{mL}$ to $1.2 \mathrm{mg} / \mathrm{mL}$, even if a decreasing trend was observed. Starting from $1.4 \mathrm{mg} / \mathrm{mL}$ of Ro EO, the effect on $\mathrm{V}$ was statistically evident $(p<0.001)$.
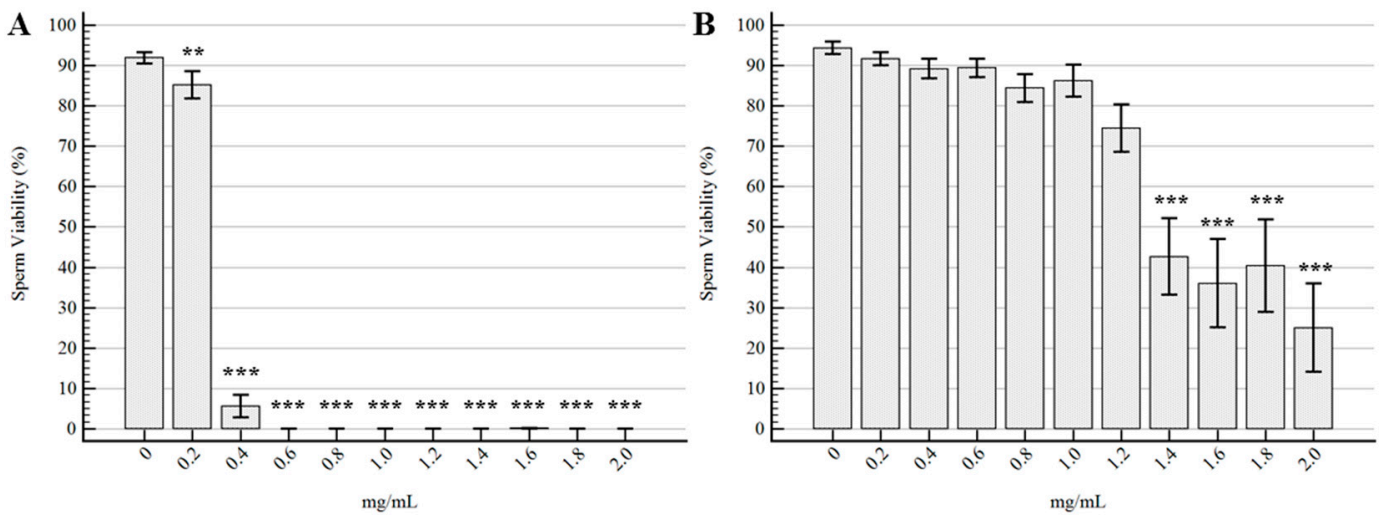

Figure 1. Effects of the EOs on sperm viability. (A) Thymbra capitata; (B) Rosmarinus officinalis. Data are expressed as mean \pm standard error of the mean $(n=6) .0 \mathrm{mg} / \mathrm{mL}$ represents the control sample (only emulsifiers). ${ }^{* *}=p<0.01{ }^{* * *}=p<0.001$.

The trends of total motility for the different samples are represented in Figure 2. The Tc EO determined a strong reduction in total motility at $0.2 \mathrm{mg} / \mathrm{mL}$, with an almost complete immobilization of spermatozoa at the other tested concentrations. On the other hand, Ro EO did not determine any significant difference in comparison to the control samples up to $0.6 \mathrm{mg} / \mathrm{mL}$, although the concentration of $0.6 \mathrm{mg} / \mathrm{mL}$ showed a mild decreasing trend $(p=0.08)$.
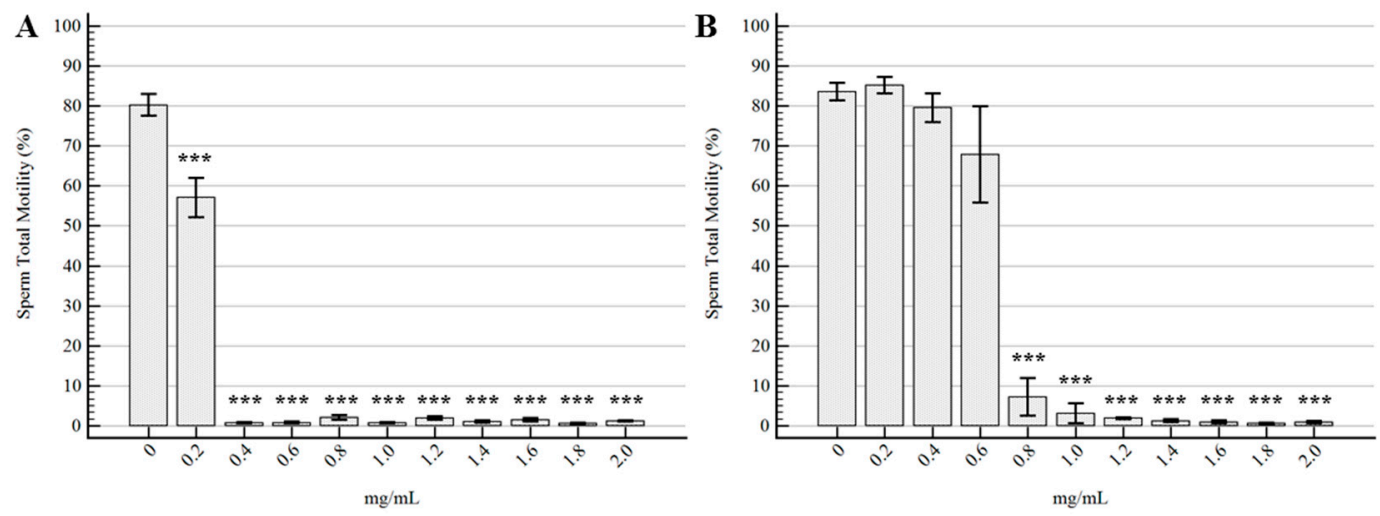

Figure 2. Effects of the EOs on total motility. (A) Thymbra capitata. (B) Rosmarinus officinalis. Data are expressed as the mean \pm standard error of the mean $(n=6)$, and $0 \mathrm{mg} / \mathrm{mL}$ represents the control sample (only emulsifiers). ${ }^{* * *}=p<0.001$.

The statistical results for ProgM (Figure S1) showed exactly the same trends and differences of TotM for both EOs. The results of the analyses of the kinematic parameters of the samples with a TotM $\geq 20 \%$ are summarized in Table S3. It was not possible to accurately analyze the kinematic parameters of the other samples (from $0.4 \mathrm{mg} / \mathrm{mL}$ of $T c \mathrm{EO}$; from $0.8 \mathrm{mg} / \mathrm{mL}$ of Ro EO) because of the extremely low number of motile cells. The velocity (velocity average path: VAP; velocity curved line: VCL; velocity straight line: VSL) and distance (distance average path: DAP; distance curved 
line: DCL; distance straight line: DSL) parameters showed the same behavior as TotM, with statistical differences starting from $0.2 \mathrm{mg} / \mathrm{mL}$ for Tc EO. Linearity (LIN), straightness (STR), and wobble (WOB) percentages, alongside with the amplitude of lateral head displacement (ALH) and the beat cross frequency $(\mathrm{BCF})$, showed no significant differences among the analyzed samples.

Regarding the percentage of acrosome reaction, the results and statistical differences are represented in Figure 3: Tc EO, at the concentration of $0.2 \mathrm{mg} / \mathrm{mL}$ did not determine any difference compared to the control sample $(p=0.93)$, whereas all the other experimental concentrations showed important differences $(p<0.0001)$. On the other hand, it was evident that the effect of Ro EO on AR was significantly different only for 1.8 and $2 \mathrm{mg} / \mathrm{mL}$, with respective $p$-values of 0.004 and 0.0003 .
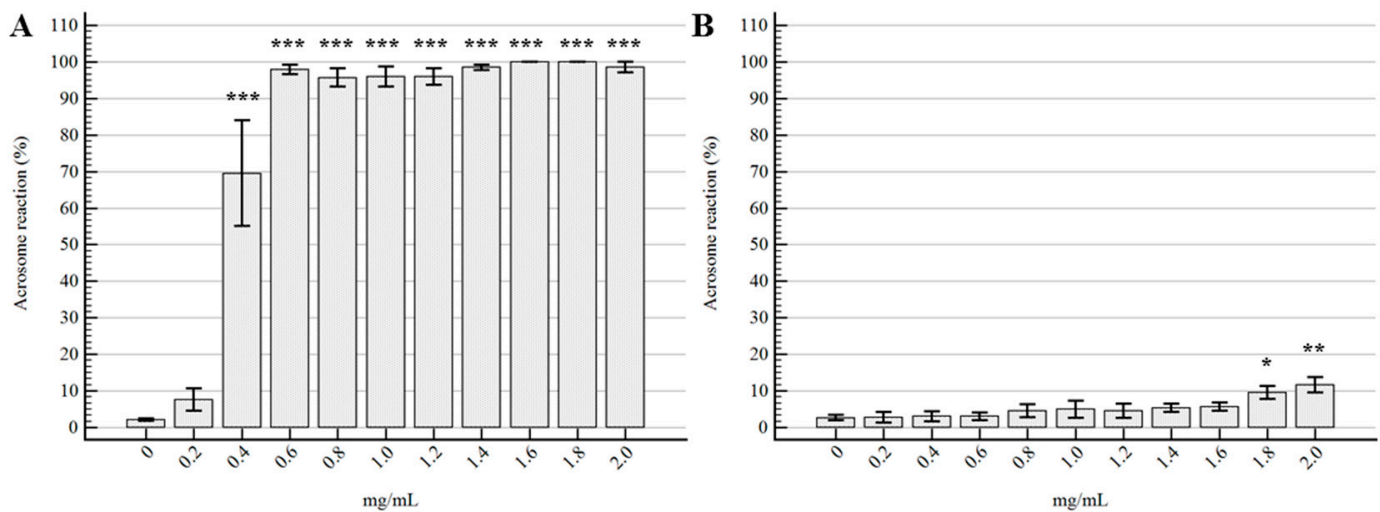

Figure 3. Effects of the EOs on acrosome status. (A) Thymbra capitata; (B) Rosmarinus officinalis. Data are expressed as mean \pm standard error of the mean $(n=6) .0 \mathrm{mg} / \mathrm{mL}$ represents the control sample (only emulsifiers). ${ }^{*}=p<0.05 ;{ }^{* *}=p<0.01{ }^{* * *}=p<0.001$.

The angular coefficients $(\beta)$ resulting from the simple linear regression models between EO concentrations and semen morpho-functional parameters are reported in Table 3.

Table 3. Simple linear regression models' angular coefficients $(\beta)$.

\begin{tabular}{ccc}
\hline \multirow{2}{*}{ Parameters } & T. capitata EO & R. officinalis EO \\
\cline { 2 - 3 } & $\beta$ (95\% C.I.) & $\beta$ (95\% C.I.) \\
& $p$ Value & $p$ Value \\
\hline \multirow{2}{*}{ V \% } & $-0.013(-0.017 ;-0.009)$ & $-0.018(-0.022 ;-0.015)$ \\
& $p<0.0001$ & $p<0.0001$ \\
\hline \multirow{2}{*}{ TotM \% } & $-0.015(-0.020:-0.010)$ & $-0.014(-0.017 ;-0.012)$ \\
& $p<0.0001$ & $p<0.0001$ \\
\hline \multirow{2}{*}{ ProgM \% } & $-0.027(-0.037 ;-0.016)$ & $-0.026(-0.031 ;-0.021)$ \\
& $p<0.0001$ & $p<0.0001$ \\
\hline \multirow{2}{*}{ AR \% } & $0.013(0.010 ; 0.016)$ & $0.086(0.052 ; 0.119)$ \\
& $p<0.0001$ & $p<0.0001$ \\
\hline \multirow{2}{*}{$\mathrm{pH}$} & $0.508(-1.168 ; 2.185)$ & $-0.018(-2.275 ; 2.238)$ \\
& $p=0.546$ & $p=0.987$ \\
\hline
\end{tabular}

C.I. = confidence interval; $\mathrm{V}=$ Viability; TotM = total motility; ProgM = progressive motility; $\mathrm{AR}=$ acrosome reaction.

\subsection{Morphological Evaluation by SEM}

Scanning electron microscopy analyses highlighted great alterations of EO-treated spermatozoa compared to both the control sample and the additional capacitated sample, as shown in Figure 4. 

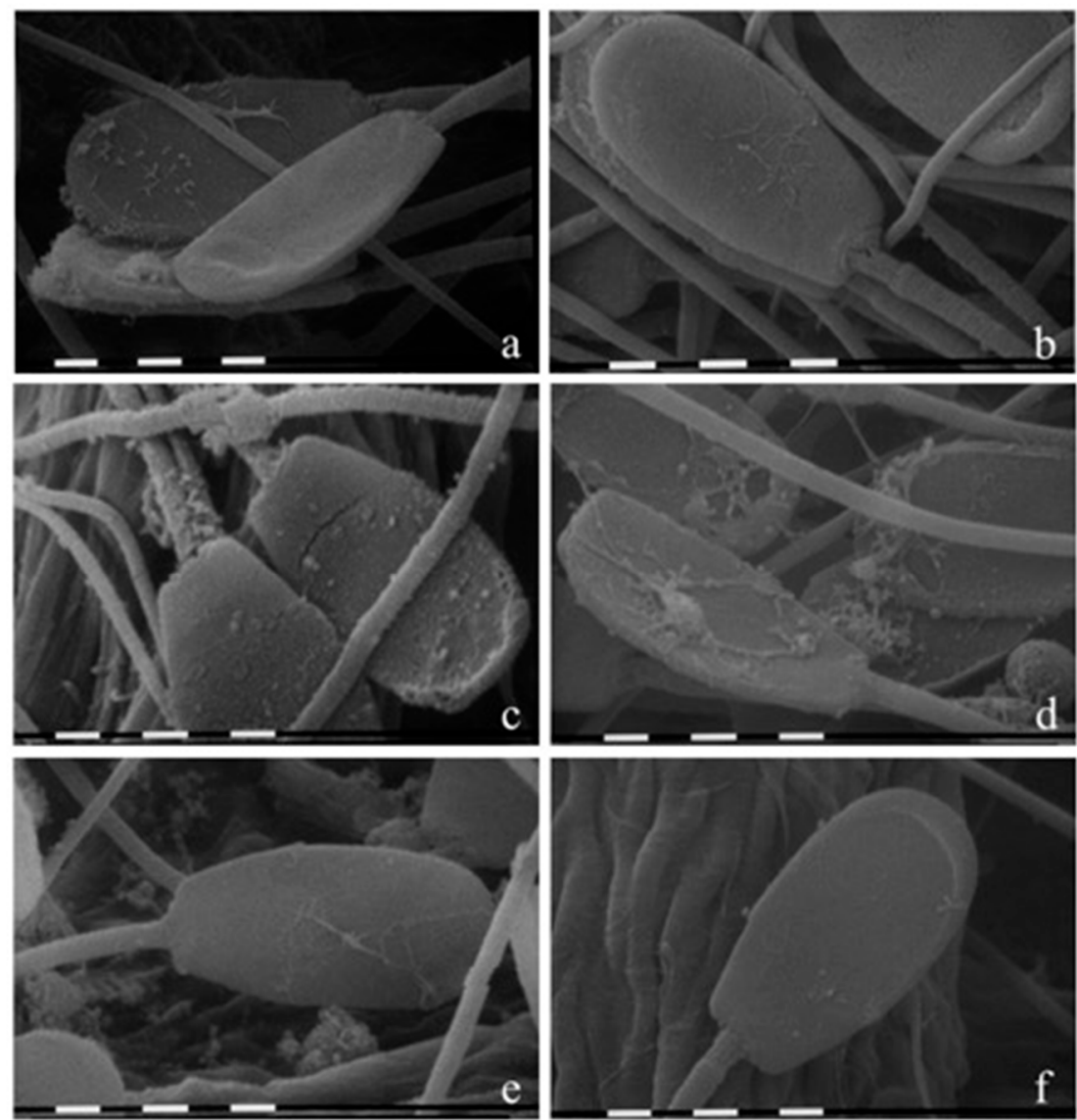

Figure 4. Scanning electron micrographs on the effect of EOs on sperm morphology. Semen samples (a) treated with $0.2 \mathrm{mg} / \mathrm{mL}$ of Thymbra capitata; (b) with $0.2 \mathrm{mg} / \mathrm{mL}$ of Rosmarinus officinalis; (c) with $2 \mathrm{mg} / \mathrm{mL}$ of $T c$; (d) with $2 \mathrm{mg} / \mathrm{mL}$ of $R o$; (e) capacitated spermatozoa; and (f) control sample (bars $=1 \mu \mathrm{m}$ ).

As expected, the control (Figure 4f) did not appear morphologically altered: the membranes were regular, smooth, and flattened, and every part of the cell was clearly distinguishable. The capacitated sample (Figure 4e) showed mild exfoliation and disruption of the head membranes in agreement with human literature [22]. On the other hand, the spermatozoa treated with the highest concentration of both EOs showed several morphology defects on the sperm membranes. As shown in Figure 4c, Tc $(2 \mathrm{mg} / \mathrm{mL})$ caused vesiculation, vacuolation, and lyses of membranes throughout the entire cell. At the same concentration, Ro (Figure 4d) only seemed to alter the head region with a different morphological aspect. Figure $4 \mathrm{a}, \mathrm{b}$ report the spermatozoa treated with $0.2 \mathrm{mg} / \mathrm{mL}$ of $T c$ and $R o$, respectively. In this case, the morphology did not seem to differ compared to the control spermatozoa.

\section{Discussion}

In the present study, different concentrations of T. capitata and R. officinalis EOs were applied to swine spermatozoa to investigate the effects on their main morpho-functional parameters. The rationale behind the work was the idea of better understanding the interactions between essential oils and male gametes in the light of the increasing interest toward natural substances and their future applications in veterinary and human reproductive medicine. Our data show clear concentration-dependent effects for both tested essential oils as confirmed by the simple linear regression models.

The results suggest that the essential oil derived from $T$. capitat $a$ induce more intense effects, even at the lowest tested concentration of $0.2 \mathrm{mg} / \mathrm{mL}$. Viability and motility are, indeed, significantly reduced, resulting in semen deterioration below the accepted quality standards. At the same 
concentration, the percentage of spermatozoa with reacted acrosomes show an increasing trend, but in a non-statistically significant manner. Starting at the concentration of $0.6 \mathrm{mg} / \mathrm{mL}$, this EO induces a complete spermicidal effect, completely altering all the investigated parameters. The Tc EO used in this study is composed by carvacrol $(65.2 \%)$ and thymol $(3.49 \%)$, compounds that comprise the majority of its phenolic content. It has already been reported that the terpene phenols, in particular carvacrol and thymol, are the major compounds responsible for the antimicrobial effects of EOs [23]. They are, indeed, capable of altering the permeability of bacterial membranes by joining to the amine and hydroxylamine groups of the membrane proteins [20]. Our hypothesis is that such a high content in phenols of this particular EO has caused alterations in the spermatozoa membrane similar to that described in bacteria. This statement seems to be strongly supported by the findings regarding the viability and acrosome status. Spermatozoa viability, when assessed with the eosin-nigrosin staining technique, is actually a measure of the cytoplasmic membrane integrity [24] since the eosin only penetrates the head of spermatozoa with disrupted outer membranes. Therefore, this parameter can be considered as an indirect index of membrane deterioration. Likewise, the staining technique used to assess the percentage of the reacted acrosome, Comassie Blue, gives us information regarding the status of the acrosomal membranes. In the case of $T_{c} \mathrm{EO}$, as previously reported, these two parameters were drastically affected, suggesting an extremely high level of membrane alterations. The above hypothesis seems to find a final iconographic validation in the SEM images, especially for the sample treated with $2 \mathrm{mg} / \mathrm{mL}$, which display severe outer alterations on the entire cell. In the light of the results achieved by the present study, T. capitata seems to have a greater potential as a spermicidal agent for reproductive medicine. Nonetheless, analyses on spermatozoa treated with lower concentrations are necessary to identify a potentially harmless concentration.

As far as it concerns the analyses regarding the R. officinalis EO, the results are clearly different. Overall, this compound seems to be well tolerated by boar spermatozoa up to the concentration of $0.6 \mathrm{mg} / \mathrm{mL}$. The membrane integrity, in terms of viability and acrosome reaction, is preserved up to concentrations of $1.2 \mathrm{mg} / \mathrm{mL}$ and $1.6 \mathrm{mg} / \mathrm{mL}$ respectively, never reaching an absolute spermicidal effect. In this case, the limiting parameter seems to be the motility, both total and progressive, which appears significantly altered starting from the concentration of $0.8 \mathrm{mg} / \mathrm{mL}$. The inhibition of motility without any structural membrane alteration, represents a different pattern of damage when compared to the one induced by the Tc EO, and proves why the motility is one of the most important and sensitive parameter when analyzing spermatozoa [25] and spermicidal substances [12]. Bakkali and colleagues have reported that, in eukaryotic cells, EOs can depolarize mitochondrial membranes by decreasing membrane potential and affecting ionic cycling [8], and this might be the reason behind the motility inhibition. Due to its relatively wider "safety window", the EO of R. officinalis may be exploited, in reproductive medicine, for its antioxidant and antibacterial effects. For instance, Chaftar et al. [26] reported that the minimum inhibitory concentration (MIC) of this EO against several strains of Legionella pneumophila is $<0.55 \mathrm{mg} / \mathrm{mL}$, a concentration that, according to the present study, would be well tolerated by spermatozoa. Further studies are necessary to confirm its potential as an antibacterial agent, for example, in artificial insemination swine doses, where antibiotics are still mandatory [13].

\section{Materials and Methods}

The EOs of Tc and Ro used in this study were kindly supplied by APA-CT S.r.l. (Via Sacco Nicola, 22 47122, Forlì, Italy). For the experimental purposes, the EOs were reconstituted in $0.5 \%$ dimethylsulfoxide (DMSO) with Tween $80(0.02 \% v / v)$ for easy diffusion [3]. 


\subsection{Chemo-Characterization of the EOs}

\subsubsection{Gas Chromatography-Mass Detector (GC-MS) Analysis}

Analyses were performed on a 7890A gas chromatograph coupled with a 5975C network mass spectrometer (Agilent Technologies, Waldbronn, Germany). Compounds were separated on an Agilent Technologies HP-5 MS cross-linked poly-5\% diphenyl-95\% dimethyl polysiloxane $(30 \mathrm{~m} \times 0.25 \mathrm{~mm}$ i.d., $0.25 \mu \mathrm{m}$ film thickness) capillary column. The column temperature was initially set at $45^{\circ} \mathrm{C}$, then increased at a rate of $2{ }^{\circ} \mathrm{C} / \mathrm{min}$ up to $100{ }^{\circ} \mathrm{C}$, then raised to $250{ }^{\circ} \mathrm{C}$ at a rate of $5{ }^{\circ} \mathrm{C} / \mathrm{min}$, and finally held for $5 \mathrm{~min}$. The injection volume was $0.1 \mu \mathrm{L}$, with a split ratio 1:20. Helium was used as the carrier gas, at a flow rate of $0.7 \mathrm{~mL} / \mathrm{min}$. The injector, transfer line and ion-source temperature was $250{ }^{\circ} \mathrm{C}, 280^{\circ} \mathrm{C}$, and $230^{\circ} \mathrm{C}$, respectively. MS detection was performed with electron ionization (EI) at $70 \mathrm{eV}$, operating in the full-scan acquisition mode in the $m / z$ range $40-400$. EOs were diluted 1:20 $(v / v)$ with $\mathrm{n}$-hexane before GC-MS analysis.

\subsubsection{Gas Chromatography-Flame Ionization Detector (GC-FID) Analysis}

Analyses were carried out on an Agilent Technologies 7820 gas chromatograph (Waldbronn, Germany) with a flame ionization detector (FID). Compounds were separated on an Agilent Technologies HP-5 crosslinked poly-5\% diphenyl-95\% dimethyl polysiloxane $(30 \mathrm{~m} \times 0.32 \mathrm{~mm}$ i.d., $0.25 \mathrm{~mm}$ film hickness) capillary column. The temperature program was the same as described above. The injection volume was $0.1 \mu \mathrm{L}$ in split mode 1:20. Helium was used as the carrier gas at a flow rate of $1.0 \mathrm{~mL} / \mathrm{min}$. The injector and detector temperature was set at $250{ }^{\circ} \mathrm{C}$ and $300^{\circ} \mathrm{C}$, respectively. EOs and the reference standards were diluted 1:20 $(v / v)$ with $n$-hexane before GC-FID analysis. The analyses were performed in duplicate.

\subsubsection{Qualitative and Semi-Quantitative Analysis}

Compounds were identified by comparing the retention times of the chromatographic peaks with those of authentic reference standards run under the same conditions and by comparing the linear retention indices (LRIs) relative to C8-C40 n-alkanes obtained on the HP-5 column under the above-mentioned conditions with the literature [27]. Peak enrichment by co-injection with authentic reference compounds was also carried out. Comparison of the MS-fragmentation pattern of the target analytes with those of pure components was performed. A mass-spectrum database search was carried out by using the National Institute of Standards and Technology (NIST, Gaithersburg, MD, USA) mass-spectral database (version 2.0d, 2005).

Semi-quantification was calculated as the relative percentage amount of each analyte; in particular, the values were expressed as the percentage peak area relative to the total composition of each $\mathrm{EO}$ obtained by GC-FID analysis.

\subsection{Boars and Ejaculate Collection}

Two adult hybrid (Large White $\times$ Duroc) boars were enrolled as sperm donors for the experiments. Animals were housed in single pens, according to the national law (D.lgs n.122/2011). Semen was routinely collected by an experienced operator twice a week using the hand-gloved technique. The sperm-rich fraction (SRF) was immediately diluted 1:1 v/v with Swine Fertilization Medium (SFM) extender prepared as previously described [28], and an aliquot (2 mL) was analyzed to assess overall quality [29]. Each SRF was evaluated for spermatozoa concentration by a Thoma haemocytometer chamber, viability and total motility, as described later.

SRF inclusion criteria for the experimental protocol were set as sperm V $>85 \%$ and TotM $>80 \%$, according to the common sperm quality standards. Twelve ejaculates, six from each boar, were included in experimental protocol. 


\subsection{Experimental Protocol}

Each EO was tested on six different ejaculates $(n=6)$ (three from each boar). The experimental doses were prepared by suspending a fixed number of spermatozoa $\left(15 \times 10^{7} \mathrm{spz}\right)$ in $5 \mathrm{~mL}$ of SFM extender (final concentration $=3 \times 10^{7} \mathrm{spz} / \mathrm{mL}$ ) with 10 different concentrations of EO (from 0.2 to $2 \mathrm{mg} / \mathrm{mL}$, at intervals of 0.2). The SFM extender was prepared as described by Fantinati et al. [28], without any antibiotic. For each experiment, control samples were realized by only adding the emulsifiers (DMSO 0.5\% $v / v$ and Tween $800.02 \% v / v$ [3]). After preparation, the experimental doses were incubated for $3 \mathrm{~h}$ in a refrigerated bath at $16^{\circ} \mathrm{C}\left( \pm 1{ }^{\circ} \mathrm{C}\right)$, and subsequently evaluated for the principal morpho-functional parameters.

\subsection{Semen Morpho-Functional Evaluations}

Viability was assessed using the Eosin-Nigrosin staining method [29]. Briefly, $10 \mu \mathrm{L}$ of staining solution were added to $10 \mu \mathrm{L}$ of each dose, and $8 \mu \mathrm{L}$ were immediately smeared on a glass microscope slide for the analysis. The percentage of live cells (undyed spermatozoa/all spermatozoa) was evaluated on a minimum of 200 cells.

Analyses regarding the acrosome status were performed using a modified Coomassie Blue staining protocol as previously described [30]. After two washings in phosphate-buffered saline (PBS), spermatozoa were fixed in $4 \%$ paraformaldehyde for $10 \mathrm{~min}$. Sperm were then centrifuged and suspended with ammonium acetate $(100 \mathrm{mM}, \mathrm{pH} 9)$. Twenty microliters were then smeared on a microscope glass slide, air dried, and incubated for 2 min with $0.22 \%$ Coomassie Blue G250 staining solution. The percentage of reacted acrosomes (AR) (undyed acrosomes/all acrosomes) was evaluated on a minimum of 200 cells. The slides prepared for the evaluation of viability and acrosome status were coded and analyzed by a blinded operator in order to avoid biases.

The objective motility of the spermatozoa, both total and progressive, and the kinematics parameters were assessed using a Computer Assisted Sperm Analysis (CASA; Hamilton Thorne CEROS II; Animal Motility II, Software Version 1.9, Beverly, MA, USA) unit. Prior to the analysis, an aliquot from each experimental sample was incubated for $10 \mathrm{~min}$ at $37^{\circ} \mathrm{C}$ in a digital incubator (INCU-Line IL23; VWR International, Radnor, PA, USA). All samples were analyzed by the same blinded operator, and at least one thousand spermatozoa for each sample were tracked. Since the kinematics parameters derive from motile spermatozoa, we decided to only report the ones for samples with a minimum TotM of $20 \%$ (at least 200 motile cells).

The $\mathrm{pH}$ of each experimental sample was analyzed using a Medidor PH BASIC 20 (Hach Lange srl, Milan, Italy) after calibration according to the instrument's instructions.

\subsection{Scanning Electron Microscopy (SEM)}

Scanning electron microscopy (SEM) studies were performed to visualize any possible membrane morphological change in the spermatozoa treated with $T c$ and Ro EOs. The samples treated with the highest and lowest concentration of each EO $(0.2$ and $2 \mathrm{mg} / \mathrm{mL})$, one control with the emulsifiers, and an additional capacitated sample [31], were analyzed with SEM. For each sample, an aliquot of $500 \mu \mathrm{L}$ was centrifuged at $800 \times g$ for $10 \mathrm{~min}$, and the pellet fixed in $500 \mu \mathrm{L}$ of $5 \%$ glutaraldehyde solution buffered at $\mathrm{pH} 7.2$ with phosphate buffer $0.1 \mathrm{M}$. The mixture was dropped by a pipette on filter paper, washed with phosphate buffer $0.1 \mathrm{M} \mathrm{pH} 7.2$, dehydrated through an increasing concentration of aqueous ethanol $(10 \%, 20 \%, 30 \%, 50 \%, 75 \%$ and $95 \%)$ for $15 \mathrm{~min}$ and in $100 \%$ ethanol for $5 \mathrm{~min}$. All the above steps were performed at $5{ }^{\circ} \mathrm{C}$. The samples were then dried with an Emitech K850 (Emitech Ltd., Ashford, UK) critical point drier unit mounted on aluminum stubs with double-sided tape and coated with gold-palladium film using an Emitech K500 (Emitech Ltd., Strovolos, Cyprus) ion sputtering unit. Samples were observed with a Philips 515 SEM scanning electron microscope (Philips, Eindhoven, The Netherlands) at $10 \mathrm{kV}$, and pictures were taken with a Nikon 5400 Coolpix digital camera (Nikon, Tokyo, Japan). 


\subsection{Statistical Methods}

The statistical analyses were performed using the software R 3.0.3 (The R Foundation for Statistical Computing). Descriptive statistics of the parameters were calculated and expressed as means and standard error of the mean. Normal distribution was assessed with the Shapiro-Wilk test $(p<0.05)$. To evaluate differences between the control doses and the others containing EOs, one-way ANOVA was performed with the significance level set at 0.05 . Post hoc analyses were performed by means of Dunnett's test $(p<0.05)$ to assess the differences between the controls and the treatments. To evaluate the presence of a concentration-dependent effect of the EOs on the morpho-functional parameters, simple linear regression models were performed.

\section{Conclusions}

In conclusion, the proposed approach to evaluate the effects of the essential oils on spermatozoa seems to be capable of providing robust and repeatable results. As expected, these cells proved to be sensitive and susceptible to external stimuli and to be capable of showing a variety of different functional patterns, providing interesting insights to the toxicity mechanisms. Overall, the results of the present work represent the first step towards the systematic characterization of the effects of these natural compounds on spermatozoa. These kinds of studies are necessary to strengthen the idea of future applications of EOs in the reproductive field for their antioxidant, antibacterial, or spermicidal properties.

Supplementary Materials: The following are available online. Table S1: Descriptive statistics of the effects of Thymbra capitata EO on semen morpho-functional parameters. Table S2: Descriptive statistics of the effects of Rosmarinus officinalis EO on semen morpho-functional parameters. Table S3: Effects of Thymbra capitata and Rosmarinus officinalis EOs on spermatic kinematic parameters. Figure S1: Effects of the EOs on Progressive Motility.

Acknowledgments: Authors would like to thank APA-CT for kindly supplying the essential oils used in this study, and Cinzia Cappannari for her technical support.

Author Contributions: M.L.B. and A.E. conceived and designed the experiments; A.E., D.V., and F.B. performed the experiments on the spermatozoa; S.B. performed the gas chromatographic analyses; A.P. and G.F. performed the electron microscopy analyses; A.E. analyzed the data; M.S. contributed reagents/materials; M.L.B., A.E., and M.S. interpreted the data; and A.E. and D.V. wrote the paper. All the co-authors approved the final draft.

Conflicts of Interest: The authors declare no conflict of interest. APA-CT did not play any role in the design of the study nor in the acquisition/interpretation of the results despite supplying the essential oils.

\section{References}

1. Chikhoune, A.; Stouvenel, L.; Iguer-Ouada, M.; Hazzit, M.; Schmitt, A.; Lorès, P.; Wolf, J.P.; Aissat, K.; Auger, J.; Vaiman, D.; et al. In Vitro effects of Thymus munbyanus essential oil and thymol on human sperm motility and function. Reprod. Biomed. Online 2015, 31, 411-420. [CrossRef] [PubMed]

2. Prashar, A.; Locke, I.C.; Evans, C.S. Cytotoxicity of lavender oil and its major components to human skin cells. Cell Prolif. 2004, 37, 221-229. [CrossRef] [PubMed]

3. Bag, A.; Chattopadhyay, R.R. Evaluation of Synergistic Antibacterial and Antioxidant Efficacy of Essential Oils of Spices and Herbs in Combination. PLoS ONE 2015, 10, e131321. [CrossRef] [PubMed]

4. Freires, I.A.; Denny, C.; Benso, B.; de Alencar, S.M.; Rosalen, P.L. Antibacterial Activity of Essential Oils and Their Isolated Constituents against Cariogenic Bacteria: A Systematic Review. Molecules 2015, 20, 7329-7358. [CrossRef] [PubMed]

5. Hayashi, K.; Kamiya, M.; Hayashi, T. Virucidal effects of the steam distillate from Houttuynia cordata and its components on HSV-1, influenza virus, and HIV. Planta Med. 1995, 61, 237-241. [CrossRef] [PubMed]

6. Schnitzler, P.; Schuhmacher, A.; Astani, A.; Reichling, J. Melissa officinalis oil affects infectivity of enveloped herpesviruses. Phytomedicine 2008, 15, 734-740. [CrossRef] [PubMed]

7. Tampieri, M.P.; Galuppi, R.; Macchioni, F.; Carelle, M.S.; Falcioni, L.; Cioni, P.L.; Morelli, I. The inhibition of Candida albicans by selected essential oils and their major components. Mycopathologia 2005, 159, 339-345. [CrossRef] [PubMed] 
8. Bakkali, F.; Averbeck, S.; Averbeck, D.; Idaomar, M. Biological effects of essential oils-A review. Food Chem. Toxicol. 2008, 46, 446-475. [CrossRef] [PubMed]

9. Hammer, K.A.; Carson, C.F.; Riley, T.V.; Nielsen, J.B. A review of the toxicity of Melaleuca alternifolia (tea tree) oil. Food Chem. Toxicol. 2006, 44, 616-625. [CrossRef] [PubMed]

10. Paul, S.; Kang, S.C. Studies on the viability and membrane integrity of human spermatozoa treated with essential oil of Trachyspermum ammi (L.) Sprague ex Turrill fruit. Andrologia 2012, 44 (Suppl. 1), 117-125. [CrossRef] [PubMed]

11. Carson, C.F.; Mee, B.J.; Riley, T.V. Mechanism of action of Melaleuca alternifolia (tea tree) oil on Staphylococcus aureus determined by time-kill, lysis, leakage, and salt tolerance assays and electron microscopy. Antimicrob. Agents Chemother. 2002, 46, 1914-1920. [CrossRef] [PubMed]

12. Lee, C.H. Review: In vitro spermicidal tests. Contraception 1996, 54, 131-147. [CrossRef]

13. EUR-Lex-52015XC0911(01)-EN-EUR-Lex. Available online: http://eur-lex.europa.eu/legal-content/EN/ TXT/?uri=CELEX:52015XC0911\%2801\%29 (accessed on 11 October 2017).

14. Hung, P.H.; Baumber, J.; Meyers, S.A.; VandeVoort, C.A. Effects of environmental tobacco smoke in vitro on rhesus monkey sperm function. Reprod. Toxicol. 2007, 23, 499-506. [CrossRef] [PubMed]

15. Condorelli, R.A.; La Vignera, S.; Giacone, F.; Iacoviello, L.; Vicari, E.; Mongioi', L.; Calogero, A.E. In vitro effects of nicotine on sperm motility and bio-functional flow cytometry sperm parameters. Int. J. Immunopathol. Pharmacol. 2013, 26, 739-746. [CrossRef] [PubMed]

16. D'Cruz, O.J.; Vassilev, A.; Uckun, F.M. Evaluation of boar sperm as a model system to study the mechanism of spermicidal activity of vanadocenes. Biochem. Biophys. Res. Commun. 2000, 270, 826-830. [CrossRef] [PubMed]

17. Althouse, G. Artificial insemination in swine: Boar stud management. In Current Therapy in Large Animal Theriogenology; Youngquist, R.S., Threlfall, W.R., Eds.; Elsevier Health Sciences: New York, NY, USA, 2006; pp. 731-738, ISBN 978-1-4377-1340-4.

18. Elmi, A.; Ventrella, D.; Barone, F.; Benvenuti, S.; Scozzoli, M.; Bacci, M.L. Preliminary evaluations of the effects of Cuminum cyminum and Coriandrum sativum essential oils on swine spermatozoa. JSM Sex. Med. 2017, 2, 1012.

19. Satyal, P.; Jones, T.H.; Lopez, E.M.; McFeeters, R.L.; Ali, N.A.; Mansi, I.; Al-Kaf, A.G.; Setzer, W.N. Chemotypic Characterization and Biological Activity of Rosmarinus officinalis. Foods 2017, 6. [CrossRef] [PubMed]

20. Bounatirou, S.; Smiti, S.; Miguel, M.G.; Faleiro, L.; Rejeb, M.N.; Neffati, M.; Costa, M.M.; Figueiredo, A.C.; Barroso, J.G.; Pedro, L.G. Chemical composition, antioxidant and antibacterial activities of the essential oils isolated from Tunisian Thymus capitatus Hoff. et Link. Food Chem. 2007, 105, 146-155. [CrossRef]

21. Carrasco, A.; Perez, E.; Cutillas, A.-B.; Martinez-Gutierrez, R.; Tomas, V.; Tudela, J. Origanum vulgare and Thymbra capitata Essential Oils from Spain: Determination of Aromatic Profile and Bioactivities. Nat. Prod. Commun. 2016, 11, 113-120. [PubMed]

22. Sathananthan, P.A.H.; Deen, F. Microscopic Images of Human Sperm, Oocytes and Embryos for Assisted Reproductive Technology Including Embryonic Stem Cells: (Multi-Author); Henry Sathananthan, A., Ed.; Professor Arunachalam Henry Sathananthan: Melbourne, Australia, 2014; ISBN 978-0-9942165-0-2.

23. Gallucci, M.N.; Oliva, M.; Casero, C.; Dambolena, J.; Luna, A.; Zygadlo, J.; Demo, M. Antimicrobial combined action of terpenes against the food-borne microorganisms Escherichia coli, Staphylococcus aureus and Bacillus cereus. Flavour Fragr. J. 2009, 24, 348-354. [CrossRef]

24. Björndahl, L.; Söderlund, I.; Johansson, S.; Mohammadieh, M.; Pourian, M.R.; Kvist, U. Why the WHO recommendations for eosin-nigrosin staining techniques for human sperm vitality assessment must change. J. Androl. 2004, 25, 671-678. [CrossRef] [PubMed]

25. Broekhuijse, M.L.; Šoštarić, E.; Feitsma, H.; Gadella, B.M. Application of computer-assisted semen analysis to explain variations in pig fertility. J. Anim. Sci. 2012, 90, 779-789. [CrossRef] [PubMed]

26. Chaftar, N.; Girardot, M.; Quellard, N.; Labanowski, J.; Ghrairi, T.; Hani, K.; Frère, J.; Imbert, C. Activity of Six Essential Oils Extracted from Tunisian Plants against Legionella pneumophila. Chem. Biodivers. 2015, 12, 1565-1574. [CrossRef] [PubMed]

27. Adams, R.P. Identification of Essential Oil Components by Gas Chromatography/Mass Spectrometry, 4th ed.; Allured Publishing Corp: Carol Stream, IL, USA, 2007; ISBN 978-1-932633-21-4. 
28. Fantinati, P.; Zannoni, A.; Bernardini, C.; Forni, M.; Tattini, A.; Seren, E.; Bacci, M.L. Evaluation of swine fertilisation medium (SFM) efficiency in preserving spermatozoa quality during long-term storage in comparison to four commercial swine extenders. Animal 2009, 3, 269-274. [CrossRef] [PubMed]

29. Barone, F.; Ventrella, D.; Zannoni, A.; Forni, M.; Bacci, M.L. Can Microfiltered Seminal Plasma Preserve the Morphofunctional Characteristics of Porcine Spermatozoa in the Absence of Antibiotics? A Preliminary Study. Reprod. Domest. Anim. Zuchthyg. 2016, 51, 604-610. [CrossRef] [PubMed]

30. Bacci, M.L.; Zannoni, A.; De Cecco, M.; Fantinati, P.; Bernardini, C.; Galeati, G.; Spinaci, M.; Giovannoni, R.; Lavitrano, M.; Seren, E.; et al. Sperm-mediated gene transfer-treated spermatozoa maintain good quality parameters and in vitro fertilization ability in swine. Theriogenology 2009, 72, 1163-1170. [CrossRef] [PubMed]

31. Bucci, D.; Isani, G.; Giaretta, E.; Spinaci, M.; Tamanini, C.; Ferlizza, E.; Galeati, G. Alkaline phosphatase in boar sperm function. Andrology 2014, 2, 100-106. [CrossRef] [PubMed]

Sample Availability: Not available.

(C) 2017 by the authors. Licensee MDPI, Basel, Switzerland. This article is an open access article distributed under the terms and conditions of the Creative Commons Attribution (CC BY) license (http://creativecommons.org/licenses/by/4.0/). 